\title{
Technological and Disruptive Innovations in a Nation's Industrialization and Leadership Development
}

\author{
Jeffrey Yi-Lin Forrest, Slippery Rock University of Pennsylvania, USA \\ Zhen Li, Texas Woman's University, USA \\ Roger A. Solano, Slippery Rock University of Pennsylvania, USA \\ David J. Doorn, West Chester University, USA
}

\begin{abstract}
The turn of this new century has been witnessing the effort of various leading developed and developing countries in their attempt to materialize next round of industrialization by emphasizing on innovations. To potentially provide guidance to such national efforts, this paper explores the relationship between technological innovation and industrialization and the importance of disruptive innovation in the development of a nation's international leadership. By employing the rigor of game theory, this work first looks at key conditions under which an established market invites competition and innovation. On top of such generally true results, it is consequently shown that technological innovation is a driving force behind industrialization and that disruptive innovation can assist a nation to become an international leader. Other than providing policy recommendations, this paper concludes with open problems for future research.
\end{abstract}

\section{KEYWORDS}

Boundary Condition, Economy, Loyal Customer, Market, Nash Equilibrium, Normalization, Strategy, Switcher

\section{INTRODUCTION}

The recent development of artificial intelligence motivates several leading nations, such as the US, Japan, France, England, and China, to embrace for the next round of industrialization. By referencing to successes of past industrializations (Rostow, 1960; Forrest et al., 2018), these nations vigorously pursue their goals by focusing on innovations, especially technological and disruptive ones. However, main stream economics provides inconsistent conditions for industrialization to emerge (Forrest et al., 2018). These current efforts of the leading nations and the inconsistencies of main stream economics naturally motivate the investigation of the following natural questions: How are technological innovation (TI) and industrialization related? And, how does disruptive innovation (DI) help a nation become a global leader?

These are important practical and theoretical questions. In particular, to maintain their leadership in the increasingly globalized world, developed nations introduce relevant policies and provide necessary governmental supports to realize their goals (Hall \& Pesenti, 2017; OSTP, 2012; Hermann et al., 2016; Government of Japan, 2015; Marc et al., 2018). On the other hand, developing countries 
face the challenge of falling further behind the developed nations economically, socially, and politically. Thus, they have to consider what to do to at least keep up with the current development across the world (Forrest et al. 2018), while possibly providing their citizens with their longed life styles (Rostow, 1960).

While similar questions have been considered in the past, conclusions have been mostly derived using data- and anecdotes-based approaches (e.g., Nasution et al., 2018). Although stated as generallytrue results, these conclusions are definitely subject to the constraints of the employed approaches and tend to be inconclusive or inconsistent (Rostow, 1960; Forrest et al., 2018). Because of such issues, Rostow (1960) calls for the development of a reliable method and efficient way of thinking to produce theoretically sound conclusions and practically useful recommendations. As an answer to this call and a major contribution to the literature, this paper establishes generally-true results for scholars and useful recommendations for nations to potentially lead the next round of industrialization. Because of the employment of the rigor and logical thinking of game theory, conclusions developed herein are not subject to the constraints of conventional data- and anecdotes-based approaches.

More specifically, this paper fills three gaps that exist in the literature. First, although there is a large body of literature on innovation, scholars have measured this concept differently (Becheikh et al., 2006). Such diversity in measurement has produced unreliable and inconsistent conclusions. Second, numerous practical failures of modernization in the past century (Forrest et al., 2018) point to the fact that the literature upon which those nations based their attempts did not truly capture the essence behind how to kick start a self-sustaining momentum of economic growth; and it did not fully grasp the systemic relationship between TIs and industrialization. Third, although various scholars, e.g., Galli (2020), have investigated the influence of TI on efficiencies of various kinds and revealed potential drivers of technological development and industrialization, our literature search does not show studies regarding roles TIs/DIs play on a nation's industrialization and development of international leadership.

The rest of this paper is organized as follows: After literature review, the market on which the rest of the paper sits is studied in terms of how to normalize such variable factors as production costs, customer reservation prices, economic entities' boundary conditions, and magnitudes of loyal-customer bases. The main results are developed regarding the relationship between TIs and industrialization, and what great potential DIs can bring to a nation. In the conclusion, recommendations for government policymakers and open questions for future research are provided.

\section{LITERATURE REVIEW}

The recent literature can be seen from different angles. Regarding TIs and improvement in efficiencies, Arocena and Sutz (2018) call for alternatives by starting with sustainability based on the position that development is no longer within any individual's reach and that the prevailing knowledge and innovation policies are socially exclusionary. Naudé and Nagler (2018) show that over the past three decades it has become increasingly difficult for Germans to transform TIs into productivity growth even with higher investment in R\&D and personnel. Miao et al. (2018) show that TIs between 2000-2015 had a significant positive effect on the energy utilization efficiency of strategic emerging industries and demonstrated a steady annual growth. Komkov and Kulakin (2018) analyze and assess the scientific and technological development in Russia during 1997-2017. Focusing on the South Asian experience, Singh (2019) finds that each industrial revolution has its own distinctive innovation, and TIs not only change economic activities but also undergo dramatic changes in skill requirements. Omamo et al. (2020) use Kenya as a case to show that intensifying social capital strengthens the accelerator mechanism of the economy and creates larger multiplier effects, and can be achieved by advancing education and R\&D capacity.

Regarding what makes particular innovative technologies grow rapidly, Zhang et al. (2018) find that policies in China, aimed at bolstering technologies, were the cause of the rapid growth in offshore 
wind power patents during 2006-2013. By analyzing Singapore's globally competitive petrochemicals industry, a case of quick development through vigorous interventions, $\mathrm{Vu}$ (2018) provides insights into the debates about industrial policy and offers valuable lessons for developing countries. Kim and Brown (2019) analyze the effect of energy-efficiency policies on lighting patenting between 19922007. Olivera (2018) discusses the industrial policy space and possibilities for industrial development in peripheral countries by stressing the constraint imposed by the current system of rules that underly international trades.

Regarding drivers of particular technologies and industrialization, Chen et al. (2018) introduce a new paradigm of holistic innovation with its theoretical framework and policy implications based on a review of typical eastern wisdom and best innovation practices. Mayer (2018) studies channels through which mechanisms of digitization can boost industrialization in developing countries. Haraguchi et al. (2019) find that successful industrialization is collectively driven by such factors as a country's initial economic conditions, factor endowments, demography and geography, and crucially supported by variables that policymakers can control.

Concerning the growth of specific technologies and markets, Tiwari et al. (2018) provide a recommendation for how to advance the commercial readiness of graphene-based products. Karlsen (2018) documents how utility companies lead their value chains by introducing new organizational principles to grow an immature sector. Du et al. (2018) find that China is becoming the main player in plug-in electric vehicle (PEV) sales through comprehensively evaluating the evolution of China's PEV industry and technology. Nikabadi and Hakaki (2018) empirically study how open innovation improves the performance of small and medium sized companies. Elharakany et al. (2018) claim that for a nation to modernize, its higher education must meet the labor-market need by producing adequate graduate output.

Enriching this empirical literature on TI and industrialization, this work employs game theory in the name of market competitions to theoretically show two important results. First, TIs are a driving force behind industrialization. Second, to become an international market leader, a nation needs to concentrate its attention/effort on both domestic and foreign DIs.

\section{THE THEORETICAL FOUNDATION OF THIS RESEARCH}

The economic market of concern is assumed to be closed, allowing free competition, where market activities are not affected by environmental factors. It is occupied by $m(=1,2, \ldots)$ incumbent regional economies, providing mutually substitutable offers. Each economy is constrained by its respective boundary conditions; and the mutually-substitutable offers possess their individually different features and functionalities. Each economy enjoys a base of loyal customers who only purchase from their preferred economy if the price is no more than their reservation value. And, there are also switchers in the marketplace whose purchases are influenced by whose price is more competitive, forcing the regional economies to compete by adjusting prices. Additionally, assume that these regional economies know each other's pricing strategies and respond by playing the Nash equilibrium through pure self-analysis.

To make our logical reasoning plausible, consider only such firms, established to satisfy a particular market demand, that are financially sustained through positive cash flows generated from meeting the demand. And the term 'proposition,' in this paper, means a statement that is arguably true based on logical reasoning.

\section{Varied Production Costs, Boundary Conditions and Customer Reservation Prices}

Although available market offers are mutually substitutable, they still possess individually different functionalities, backed by varied levels of services. For regional economy $i$, its price $P_{i}$ satisfies $C_{i} \leq P_{i} \leq M_{i}$, where $C_{i}$ is the production cost, $M_{i}$ the reservation price of loyal customers. Then 
based on the assumption of why a company exists, $P_{i}=C_{i}+\alpha_{i}\left(M_{i}-C_{i}\right), i=1,2, \ldots, m$, for some $\alpha_{i}$ from the interval [0,1]. Instead of competing by using the absolute price $P_{i}$, the regional economies compete by adjusting $\alpha_{i}, i=1,2, \ldots, m$, to see who is more competitive.

Lemma 1. The afore-described regional economies compete with each other by adjusting $\alpha_{i}$, $0 \leq \alpha_{i} \leq 1, i=1,2, \ldots, m$. If $\alpha_{i}$ 's are seen as normalized $P_{i}$, then the costs and reservation prices of the regional economies are respectively normalized to 0 and 1 .

In the following, selling price $P_{i}$ will be identified with $\alpha_{i}$. Without causing confusion, symbol $P$ will still represent price $\left(=\alpha_{i}\right)$. Additionally, each economy is limited by its unique constraints due to the availability of resources, be they tangible or intangible (Harmancioglu et al., 2009), that a business entity can employ in designing and implementing its strategies (Barney \& Arikan, 2001). For example, each regional economy has its unique set of beliefs, organizational culture, historical tradition, industrial structure, patterns of capital flows, policy supports, etc. Such resource-based view (Kozlenkova et al., 2014) implies that different economies possess different systems of available resources, where each system is made up of a set of component resources and a set of particular associations between the component resources. This defines resource heterogeneity, see Peteraf \& Barney (2003) for firm-level discussions. These differences in resource systems realistically persist due to practical difficulties of trading resources and of connecting available resources in particular ways. That is the so-called resource immobility; for firm-level discussions along this line see (Barney $\&$ Hesterly, 2012). Performance deviations in regional economies stem from differences in available resources, their associations, and levels of resource efficiency. For a systemic investigation of resourcebased phenomena, see (Forrest et al., 2020).

Symbolically, label the factors involved in the production and marketing of the market offers by $x_{1}, x_{2}, x_{3}, \ldots$ Then, the previous paragraph implies that for regional economy $i$ ( $=1,2, \ldots, m)$, its magnitude $N_{i}\left(x_{1}, x_{2}, x_{3}, \ldots\right)$ of the base of loyal customers, reflecting how available resources are organized acceptably both internally and externally, is constrained by its lower $L_{i}\left(x_{1}, x_{2}, x_{3}, \ldots\right)$ and upper boundary $U_{i}\left(x_{1}, x_{2}, x_{3}, \ldots\right)$ : $L_{i}\left(x_{1}, x_{2}, x_{3}, \ldots\right) \leq N_{i}\left(x_{1}, x_{2}, x_{3}, \ldots\right) \leq U_{i}\left(x_{1}, x_{2}, x_{3}, \ldots\right)$. Therefore, there is a unique number $\beta_{i}$ in the interval $[0,1]$ satisfying $N_{i}\left(x_{1}, x_{2}, x_{3}, \ldots\right)=L_{i}\left(x_{1}, x_{2}, x_{3}, \ldots\right)+\beta_{i}\left[U_{i}\left(x_{1}, x_{2}, x_{3}, \ldots\right)-L_{i}\left(x_{1}, x_{2}, x_{3}, \ldots\right)\right]$. The result below follows.

Lemma 2. The lower and upper boundary conditions of the afore-described regional economies can be normalized to 0 and 1 , respectively, and the magnitudes of their loyal-customer bases normalized to values between 0 and 1 , inclusively.

In the following, the magnitude of regional economy $i$ 's loyal-customer base will be denoted as $\beta_{i}$, and total number of switchers as $\beta$, satisfying $1-\sum_{i=1}^{m} \beta_{i}, 0 \leq \beta_{i}, \beta \leq 1, i=1,2, \ldots$, $m$. 


\section{The Practicality of Pricing Strategies}

Lemma 3. In the Nash equilibrium of the afore-described market, no pure pricing strategy exists for the regional economies.

Proof. For any pure pricing strategy portfolio $\left(x_{1}, x_{2}, \ldots, x_{m}\right)$, if a unique $i \in\{1,2, \ldots, m\}$ exists $\underset{x_{i}}{\operatorname{satisfying}}<x_{j}$, for $j \in\{1,2, \ldots, m\}, j \neq i$,

then regional economy $i$ has successfully won over all switchers and can therefore raise its price $x_{i}$, but still satisfying equation (1), to bring in additional profits, while other regional economies hold their strategies unchanged. So, the chosen portfolio $\left(x_{1}, x_{2}, \ldots, x_{m}\right)$ is not a Nash equilibrium.

If there are $k$ regional economies that charge the lowest price, then these economies jointly absorbed all switchers. When one of these economies lowers its price slightly, it creates additional profits by attracting all switchers. So, the portfolio $\left(x_{1}, x_{2}, \ldots, x_{m}\right)$ is not a Nash equilibrium.

If $k=m$, then the previous discussion proves that in the Nash equilibrium, the market doesn't have any symmetric pure strategy portfolio.

Lemma 4. If all normalizations in Lemmas 1 and 2 apply, then in the Nash equilibrium, the magnitude

$\beta_{k}$ of the loyal-customer base and the price distribution $F_{k}(P)$ of regional economy $k$ satisfy

$F_{k}(P)=1-\frac{1}{\beta_{k}}\left(\frac{(1-P) \prod_{i=1}^{m} \beta_{i}}{\beta P}\right)^{\frac{1}{m-1}}, k=1,2,3, \ldots$

$F_{k}(1)=\operatorname{land} F_{k}\left(\frac{\beta_{k}}{\beta_{k}+\beta}\right)=0$.

Proof. Regional economy $k$ 's profits from its loyal customers are $\beta_{k} P$ and those from switchers are $\prod_{i=1, i \neq k}^{m}\left[1-F_{i}(P)\right] \beta P$. So, regional economy $k$ 's objective function is

$\max _{F_{k}(P)} E\left(\Pi_{k}\right)=\int_{-\infty}^{+\infty}\left\{\beta_{k} P+\prod_{i=1, i \neq k}^{m}\left[1-F_{i}(P)\right] \beta P\right\} d F_{k}(P)$,

where $\Pi_{k}$ is regional economy $k$ 's profits, $E\left(\Pi_{k}\right)$ expected profits, and economy $k$ maximizes its expected profits by selecting price distribution $F_{k}(P)$.

Regional economy $k$ 's equilibrium indifference condition is 
$\beta_{k} P+\prod_{i=1, i \neq k}^{m}\left[1-F_{i}(P)\right] \beta P=\beta_{k}, k=1,2,3, \ldots$

which implies: for $k=1,2, \ldots, m$,

$\left[1-F_{1}(P)\right] \ldots\left[1-F_{k-1}(P)\right]\left[1-F_{k+1}(P)\right] \ldots\left[1-F_{m}(P)\right] \beta P=\beta_{k}(1-P)$

Dividing the $i$ th equation by the $j$ th from equation (6), for $i, j=1,2, \ldots, m, i \neq j$, produces

$1-F_{j}(P)=\frac{\beta_{i}}{\beta_{j}}\left[1-F_{i}(P)\right]$.

By letting $i=1$ and $j=2,3,4, \ldots, m$, equation (7) leads to

$1-F_{j}(P)=\beta_{1}\left[1-F_{1}(P)\right] / \beta_{j}, j=2,3, \ldots, m$.

Substituting equation (8) into equation (5) creates

$\beta_{1}\left[1-F_{1}(P)\right]=\left(\frac{(1-P) \prod_{i=1}^{m} \beta_{i}}{\beta P}\right)^{\frac{1}{m-1}}$.

So, letting $i=k, j=1,2, \ldots, m$, and $j \neq k$, produces

$\beta_{k}\left[1-F_{k}(P)\right]=\left(\frac{(1-P) \prod_{i=1}^{m} \beta_{i}}{\beta P}\right)^{\frac{1}{m-1}}, k=1,2,3, \ldots$ So, equation (2) follows. Regarding equation (3), the first part can be verified directly. For the second part, because regional economy $k$ attempts to increase its profits by attracting switchers from the guaranteed level $\beta_{k}$ from its loyal consumers by charging them the reservation value 1 , the following holds $\beta_{k} P+\beta P \geq \beta_{k}$. So, $P \geq \beta_{k} /\left(\beta_{k}+\beta\right)$ and the second part in equation (3) follows.

Corollary 1. In the Nash equilibrium, a symmetric mixed strategy exists in the afore-described market, if and only if the magnitudes of the loyal-customer bases of the regional economies are the same.

Proof:Fromequation(2)orequation(9), $\beta_{i}\left[1-F_{i}(P)\right]=\beta_{j}\left[1-F_{j}(P)\right], i, j=1,2, \ldots, m$. So, $F_{i}(P)=F_{j}(P)$, if and only if $\beta_{i}=\beta_{j}$, for $, i, j=1,2, \ldots, m$. 


\section{Loyal-Customer Bases of Different Magnitudes}

Lemma 5. If all parameters are normalized as in Lemmas 1 and 2, then in Nash equilibrium the magnitudes of all loyal-customer bases are all equal.

Proof. Assume the opposite that let

$$
\beta_{k}=\max \left\{\beta_{1}, \beta_{2}, \ldots \beta_{m}\right\}
$$

for some $k, 1 \leq k \leq m$, and $k_{0}, 1 \leq k_{0} \leq m$, satisfy $\beta_{k}>\beta_{k_{0}}$. From equation (4), regional economy $k$ 's expected profits in Nash equilibrium are

$$
\begin{aligned}
& E\left(\Pi_{k}\right)=\int_{-\infty}^{+\infty}\left\{\beta_{k} P+\prod_{j=1, j \neq k}^{m}\left[1-F_{j}(P)\right] \beta P\right\} d F_{k}(P) \\
& =\int_{\frac{\beta_{k}}{\beta_{k}+\beta}}^{1} \beta_{k} d F_{k}(P)=\left.\beta_{k} F_{k}(P)\right|_{\frac{\beta_{k}}{\beta_{k}+\beta}} ^{1} . \text { fromequation }(5) \\
& =\beta_{k}\left\{\frac{1}{\beta_{k}}\left[\frac{\left(1-\frac{\beta_{k}}{\beta_{k}+\beta}\right) \prod_{j=1}^{m} \beta_{j}}{\frac{\beta \beta_{k}}{\beta_{k}+\beta}}\right]^{\frac{1}{m-1}}\right\}, \text { fromequation }(2)=\left(\prod_{j=1, j \neq k}^{m} \beta_{j}\right)^{\frac{1}{m-1}} .
\end{aligned}
$$

The nature of loyal consumers implies

$E\left(\Pi_{k}\right)=\left(\prod_{j=1, j \neq k}^{m} \beta_{j}\right)^{\frac{1}{m-1}} \geq \beta_{k}=(\underbrace{\beta_{k} \beta_{k} \ldots \beta_{k}}_{m-1 \text { times }})^{\frac{1}{m-1}}$, which is impossible, because based

on the assumption in equation (10), $\left(\prod_{j=1, j \neq k}^{m} \beta_{j}\right)^{\frac{1}{m-1}}<(\underbrace{\beta_{k} \beta_{k} \ldots \beta_{k}}_{m-1 \text { times }})^{\frac{1}{m-1}}=\beta_{k}$, where for every $j=1,2, \ldots, m, j \neq k, j \neq k_{0}, \beta_{j} \leq \beta_{k}$ and $\beta_{k_{0}}<\beta_{k}$. So, the magnitudes of the loyal-customer bases of the regional economies must all be equal.

Corollary 2. In the afore-described market, regional economy $k$ 's price distribution $F_{k}(P)$ of the existing symmetric mixed strategy is 


$$
\begin{aligned}
& F_{k}(P)=F(P)=1-\left[\frac{(1-P) \alpha}{\beta P}\right]^{\frac{1}{m-1}}, k=1,2,3, \ldots, \text { where } \alpha \text { is the constant } \\
& \text { magnitude of a loyal-customer base satisfying } F(P)=\operatorname{land} F(P)\left(\frac{\alpha}{\alpha+\beta}\right)=0 .
\end{aligned}
$$

Proof. This result follows readily from Corollary 1 and Lemma 4.

\section{TECHNOLOGICAL INNOVATIONS AND INDUSTRIALIZATION: THE MAIN RESULTS}

Since the time when Adam Smith (1776) first recognizes the importance of innovation in wealth creation, a large body of knowledge on innovation has been created. However, that general knowledge does not have a solid foundation, because the concept of innovation is understood differently from one study to another (Becheikh et al. 2006). To avoid inconsistent empirical proxies of innovation, as is in the literature, this section rigorously establishes two theorems on how regional economies compete against each other, then investigates the association among innovation, TI and industrialization, and what great potentials DIs can bring to an ambitious nation that desires to become a market leader.

\section{How Regional Economies Compete With Each Other}

Motivated by the universal desire for better living, the importance of industrialization, and how technologies underlie each industrialization, many countries in the $20^{\text {th }}$ century spent great amounts of energy and immense efforts to industrialize themselves. They invested heavily and adopted various policies, as suggested by development economics. They successfully attracted foreign direct investments, employed most current technologies, and established manufacturing industries in major cities and commercial centers (Acemoglu \& Robinson, 2012). However, their longed industrialization did not occur (Forrest, et al., 2018), although their rates of investment were high, and their GDP grew tremendously within short periods of time before failing (Forrest et al., 2018). The reason of these failures is that the referenced literature did not reveal the essence of how to kick-start and maintain momentums of growth and did not grasp the systemic relationship between TIs and industrialization (Forrest et al., 2018). To fill this gap in knowledge and to understand how different regional economies compete against each other, we have:

Theorem 1. In Nash equilibrium of the afore-described market, if the market proportion of switchers is greater than 0 , then at least another regional economy will profitably enter this market with its substitute offer, as a competitor of the incumbent economies, and the total expected profit of all the entering economies will be directly proportional to $\beta$.

Proof. Based on all lemmas, assume that one new regional economy enters the said market by uniformly randomizing its price $P$ over the interval $[0,1]$ (equivalently, the interval from the cost of production to the expected maximum selling price) so that it expectedly makes profits and establishes itself within the market.

To face the disruption of the established market order, each incumbent economy sets its price by considering the price of the entrant and those of other incumbent economies. Equation (5) and Lemma 4 imply that regional economy $k$ 's equilibrium indifference condition is $\beta_{k} P+\beta P(1-P) \prod_{j=1, j \neq k}^{m}\left[1-F_{j}(P)\right]=\beta_{k}$ or 
$\alpha P+\beta P(1-P)[1-F(P)]^{m-1}=\alpha$,

where $\alpha$ is the constant magnitude of any incumbent-economy's loyal-customer base. Equation

(11) implies $F(P)=1-\left(\frac{\alpha}{\beta P}\right)^{\frac{1}{m-1}}$, which is defined when $1 \geq P \geq \alpha / \beta$, because $F(P) \geq 0$. The entering-economy's expected profits are

$$
E_{e}(\Pi)=\int_{-\infty}^{\alpha / \beta} \beta P d P+\int_{\alpha / \beta}^{+\infty} \beta P[1-F(P)]^{m} d P
$$

Because $0 \leq P \leq 1$ and $F(P)$ has a mass point of size $(\alpha / \beta)^{\frac{1}{m-1}}$ at $P=1$, rewrite equation (12) as:

$$
E_{e}(\Pi)=\beta\left\{\int_{0}^{\alpha / \beta} P d P+\int_{\alpha / \beta}^{1} P[1-F(P)]^{m} d P+\left(\frac{\alpha}{\beta}\right)^{\frac{m}{m-1}}\right\}
$$

Because the expression within the braces is a real number, equation (13) implies that the entering economy expects to make a profit that is positively proportional to the magnitude of switchers.

The following is a restatement of Theorem 1 with all normalizations from Lemmas 1-5 removed. The omitted proof can be constructed according to that of Theorem 1 in Zhao et al. (2018). Note: This result only talks about market competitions without addressing what the government is concerned about, to this end, one example is (Aslani et al., 2018), where the macro-level complexity of the natural gas energy system is studied, while showing how affordability, acceptability, and reliability of energy supply are key concerns of the government.

Theorem 2. Assume that the market of concern consists of regional economies, as defined below, is in Nash equilibrium. If the proportion of switchers is greater than the minimum proportion of the loyal-customer bases of the incumbent economies, then another regional economy can profitably enter the market with substitute offer, as a competitor of the incumbent economies. Additionally, the expected profit of the entrant can be potentially as large as that of some incumbents. Here, the market satisfies: (i) it is served by $m$ incumbent regional economies with substitutable offers, $m=1,2, \ldots$; (ii) each incumbent economy enjoys the backing of loyal customers who only purchase from their favorite economy if the price is not more than their reservation value; (iii) the incumbent economies compete over those switchers who make purchases depending on whose price is more competitive; and (iv) these incumbent economies are well aware of the pricing strategies of each other and respond by playing the Nash equilibrium through pure self-analysis.

\section{Relationship Between Technological Innovation and Industrialization}

By innovation, it means a collection of one or several activities underlying the design and production of one market offer or a bundle of offers that create exceptional value for an economic entity, such as a firm or economy, when compared to other activities taking place simultaneously in the same 
market. Here, 'one market offer' represents an original creation that is of exceptionally added value for the underlying economic entity. Hence, innovation means all necessary details for introducing an offer, such as business model, operating processes, marketing efforts, etc. 'A bundle of offers' means packaging several offers into one deliverable package, where the underlying innovativeness lies in the potential creation of simultaneous consumer utilities and multi-sided markets, for which consumers are happy to bear higher prices than the market norm when the bundled offers are sold separately. The stress on comparatively added value makes this definition of innovation include many practical aspects, such as creativities of exceptional degree and quality, both internal and external acceptance, adoption of appropriate operating processes for value creation and capture, inventions and their conversion to actual products, etc.

A technological innovation (TI) represents an innovation (Welch, 2019) that emphasizes technology as a source of innovation. So, when technology is a factor for increasing a firm's competitiveness, one deals with a TI. For example, as an incredibly complex system, a nuclear plant's success depends heavily on technology. Presently, such plants represent a common way to provide power. However, for such a plant to drastically increase its market competitiveness, the management likely needs to introduce necessary innovations on the underlying technology. This concept of TI reflects the business consideration of creating and/or capturing value by working on technological aspects of market offers. Creating and capturing value generally involve the combination, integration and interaction of different technologies, on which other concepts, such as business models, management strategies, etc., play their corresponding roles.

By industrialization, it means a period when an industry, more advanced than the extant ones, is introduced to an economy on a large scale so that the accompanying social and economic changes transform the consumers into an industrial society of a higher level. An extensive reorganization of the economy occurs for the purpose of production and consumption of much improved quality. During this period, the per-capita income tends to rise, and all types of markets either emerge or expand, providing further stimuli for industrial investment and growth (O'Sullivan \& Sheffrin, 2003). The most well-known and intensively-studied industrialization is the one of England, followed by those of the United States and modern China (Forrest et al., 2018).

As for Theorem 2, its assumptions mean that each incumbent economy's internal market is in a state of mutual forbearance, where firms manufacturing the substitutable offers mitigate rivalry by dividing the market in proportions to their strengths (Bernheim \& Whinston, 1990). Doing so makes these firms yield dominance to stronger competitors in their less efficient market segments, while exchanging the latter for the same in market areas where the former are more efficient. Such codependence of domestic firms progressively persuades them to decrease their rivalry. Hence, interfirm hostility declines gradually. That is, all manufacturing firms within an incumbent regional economy in the greater market can be seen theoretically as one large aggregate company that competes with other regional aggregate companies at the international level. Additionally, the assumptions in Theorem 2 mean generally that the technology used in production and the pertinent business operations have been standardized. Hence, for a regional economy to profitably enter such a market, this economy will have to introduce a more efficient technology, and/or a more productive operation system, and/or a more functional managerial routine, such as a business model, that significantly reduce the overall expenditure in producing its market offer of increased sophistication, as partially confirmed by Christensen et al. (1998).

For an offer to successfully meet market demand, it has to stay in tune with incessantly varying consumer preferences. As described in Theorems 1 and 2, the consumer surplus of any market tends to progressively expand unless the competing regional economies, incumbent or not, unceasingly improve their offers. To accomplish this end, TIs will help either enhance an existing offer or improve business efficiency. When one link of the adopted business process is enriched by a new TI, the increased efficiency of that link will force other parts and links of the process to improve by introducing relevant TIs. Over time, the collection of all relevant TIs, introduced at different times, 
will become a recognized industry, which produces the hard gears needed for implementing the TIs in various productions. That is exactly what happened multiple times in modern history with each round of industrial revolution. For example, when human labors were replaced by machines, industries appeared promptly to make those machines. With a widening range of applications of those machines industries also appeared to provide different forms of energies, to produce locomotives, to construct necessary infrastructures, and to make needed raw materials, such as chemicals, etc. (Forrest et al., 2018). Hence, TIs is a driving force behind the development of an industrialization. Summarizing the discussions above, Theorems 1 and 2 obliquely imply:

Proposition 1. Technological innovations represent a driving force behind the appearance and development of an industrialization.

\section{Disruptive Innovations: Their Role in Leadership Development}

By disruptive innovation (DI), it means an innovation that disrupts an existing market and value system through creating a new market and new value network, with established business entities, market offers, and business alliances displaced by new ones (Christensen, 1997). This definition of DIs and Theorems 1 and 2, where "regional economy" is replaced by "enterprise" or "firm", jointly imply that DIs tend to come from non-market-leading companies, because these innovations generally require a sufficiently long period of time to become profitable, if lucky. Within such a long period of time, each DI requires additional R\&D to become deliverable offers to the market and usable offers to consumers; downstream infrastructures might also need to be constructed for the imagined products to eventually reach end users. Most critically, a consumer market of sufficient depth and magnitude needs to be formed. Hence, market-leading companies cannot afford in terms of time, finance and market rivalry to spend their resources away from their sustaining activities that are necessary to stave off competitors from encroaching on their current market positions (Christensen, 1997).

Now, Theorems 1 and 2 imply that when a market of sufficient depth and magnitude emerges, one or more established economic entities will likely enter this new market. These entrants expect to collectively make as much expected profit as the incumbent supplier whose loyal-customer base is of the minimum magnitude. And if the market expands quickly, these entrants expect to potentially make more than any of the early entrants and the initial market creators. And, once such a new product market emerges, it penetrates and creates great shocks on all or many other established markets (Assink, 2006). This also encourages economic entities of the established markets to migrate into the emerging market.

Relevant to this discussion, Lieberman and Montgomery (1988) propose the concept of first mover advantage (FMA). They show how extra time over later entrants allows for first or early movers to capture customers and build capabilities so that they can advance and perpetuate early gains. At the same time, other studies suggest (e.g., Lieberman \& Montgomery, 2013, and references listed therein) that time can also benefit later entrants by helping them to improve risk estimations, clear uncertainties, improve capability gaps, and facilitate learning from the costly mistakes of earlier entrants. The dilemma that the same logic that explains why first movers achieve better outcomes is also applicable for explicating why later entrants enjoy advantages over first movers is mainly caused by missing data, where records of failed first movers are not well recorded and therefore mostly unavailable. To resolve this dilemma, Theorems 1 and 2 imply that market leaders are generally later entrants to emerging markets. In other words, established business entities are generally not early movers of any newly emerging market until some first movers have demonstrated the existence and depth of the market. This result theoretically confirms the empirical finding (e.g., Dobrev \& Gotsopoulos, 2010) that early followers are more successful than pioneers because long-term survival and performance depend on the ability to acquire and leverage resources and capabilities for large-scale production of 
products. Summarizing this discussion, we have established the following conclusion. That, in turn, shows the importance of DIs in economic development.

Proposition 2. For a nation to potentially become a market leader quickly in the international arena, the nation needs to concentrate its attention and effort on disruptive innovations, be they created locally or come from abroad.

This conclusion follows from Theorems 1 and 2. Specifically, identify an ambitious nation, as a large, multi-business entity, which desires to become a market leader as one of the new entrants in these Theorems, while other nations that are already in the marketplace as the incumbents. Then, when some DIs demonstrate their market validity, the ambitious nation's attention and efforts spent on these innovations will quickly turn into coordination and deployment of resources and complementary capabilities to scale up its operation. The timely action can assist the nation in bypassing other nations, be they first movers in the new market or leaders of established markets.

By emerging and rising alongside the expanding market, such a nation will conveniently become a leader in the relevant international arena. As for whether or not there is a need for intellectual property protection in order for this conclusion to hold true, the anecdotal-based research of McGrath (2013) on competitive advantages and the game-theory-based work of Zhao et al. (2018) on trade dumping and anti-dumping demonstrate that such protection is not needed due to the reasons that all competitive advantages have become transient and that antidumping measures simply do not work in a globalizing market. For partial, empirical confirmations relevant to this proposition, see, for example, Markides and Geroski (2005).

\section{CONCLUSION}

By employing the rigor and logical thinking of game theory, this paper explores the relationship between TIs and industrialization by addressing an academically and practically significant question of how DIs can assist a nation to become a global leader. It contributes to the literature by establishing the following general results, although some aspects of them were previously conjectured empirically by various scholars (see the sections above for related references): (i) by treating the interaction among business entities as a game, conditions under which an established market calls for innovation and competition are established. (ii) TIs drive the appearance and development of industrialization. And, (iii) DIs can assist a nation to become a market leader internationally.

In terms of managerial recommendations, because the method of reasoning used in this paper is not subject to the constraints of empirical analysis, the established conclusions in the previous sections provide government officials and policymakers with dependable bases to make their decisions. In particular, the following general recommendations become available for the government of a nation: (i) it needs to adopt policies that inspire its citizens to innovate. If successful, the nation will motivate its manufacturing sector to constantly interpret market signals (Theorems 1 and 2). Consequent innovations will surely help direct entrepreneurial efforts productively (Naudé \& Nagler, 2018) and further the development of human capital (Arocena \& Sutz, 2018). (ii) It needs to carefully follow up the development of DIs, implement relevant policies and provide necessary supports, such as, for example, those needed for alternatively powered vehicles (Du et al., 2018), and those needed for utilizing modern technologies for effective farming in even extremely difficult environmental conditions as conventionally seen (Snyder et al., 2020), if the nation does not want to fall behind the global development (Proposition 2). As pointed out by Forrest et al. (2018), government supports are necessary for the formation of large-scale coordination, construction of infrastructure, development of markets of sufficient depth, etc. 
Regarding limitations, all conclusions established above are developed on the assumption of why a business firm exists - it attempts to satisfy a particular market demand through generating enough profits from its market offers. In real life, although this assumption used to be generally true (Sobel, 1999), it can be questioned within the current business landscape. For example, in recent years quite a few companies have been very successful by focusing on painting bright futures instead of generating positive cash flows from the marketplace. By doing so, they uninterruptedly pull in sufficient amounts of venture capital to support their operations (Li \& Ma, 2015). So, by altering this assumption in one way or another, all the results derived in this paper need to be revisited in order to develop their corresponding versions. That represents opportunities for future research that will provide useful guidelines for current business operations. 


\section{REFERENCES}

Acemoglu, D., \& Robinson, J. (2012). Why nations fail - The origins of power, prosperity, and poverty. Crown Business. doi:10.1355/ae29-2j

Arocena, R., \& Sutz, J. (2018). Re-thinking innovation as a lever for development: Taking into account inequality. In Spanish Philosophy of Technology (pp. 125-138). Springer.

Aslani, A., Akbari, S., \& Tabasi, S. (2018). The robustness of natural gas energy supply: System dynamics modelling. International Journal of System Dynamics Applications, 7(3), 57-71. Advance online publication. doi:10.4018/IJSDA.2018070103

Assink, M. (2006). Inhibitors of disruptive innovation capability: A conceptual model. European Journal of Innovation Management, 9(2), 215-233. doi:10.1108/14601060610663587

Barney, J., \& Arikan, A. (2001). The resource-based view: Origins and implications. In M. Hitt, R. Freeman, \& J. Harrison (Eds.), Handbook of strategic management (pp. 124-185). Blackwell.

Barney, J., \& Hesterly, W. (2012). Strategic management and competitive advantage: Concepts and cases (4th ed.). Pearson.

Becheikh, N., Landry, R., \& Amara, N. (2006). Lessons from innovation empirical studies in the manufacturing sector: A systematic review of the literature from 1993 to 2003. Technovation, 26(5), 644-664. doi:10.1016/j. technovation.2005.06.016

Bernheim, B. D., \& Whinston, M. D. (1990). Multimarket contact and collusive behavior. The RAND Journal of Economics, 21(1), 1-26. doi:10.2307/2555490

Chen, J., Yin, X. M., \& Mei, L. (2018). Holistic innovation: An emerging innovation paradigm. International Journal of Innovation Studies, 2(1), 1-13. doi:10.1016/j.ijis.2018.02.001

Christensen, C. M. (1997). The Innovator's dilemma: When New Technologies Cause Great Firms to Fail. Harvard Business School Press.

Christensen, C.M., Suárez, F.F., \& Utterback, J.M. (1998). Strategies for Survival in Fast-Changing Industries. Management Science, 44(12-part-2), S207-S220.

Dobrev, S. D., \& Gotsopoulos, A. (2010). Legitimacy vacuum, structural imprinting, and the first mover disadvantage. Academy of Management Journal, 53(5), 1153-1174. doi:10.5465/amj.2010.54533229

Du, J. Y., Meng, X. F., Li, J. Q., Wu, X. G., Song, Z. Y., \& Ouyang, M. G. (2018). Insights into the characteristics of technologies and industrialization for plug-in electric cars in China. Energy, 164(1), 910-924. doi:10.1016/j. energy.2018.09.060

Elharakany, R. A., Moscardini, A., Khalifa, N. M., \& Elghany, M. M. A. (2018). Modelling the effect on quality of information and communications technology (ICT) facilities in higher education: Case Study - Egyptian universities. International Journal of System Dynamics Applications, 7(3), 1-30. Advance online publication. doi:10.4018/IJSDA.2018070101

Forrest, Y. L. J., Buttermore, J., \& Wajda, T. A. (2017). At Nash equilibrium when new market competitions appear? Kybernetes, 46(2), 256-271. doi:10.1108/K-11-2016-0311

Forrest, J. Y.-L., Zhao, H. C., \& Shao, L. (2018). Engineering Rapid Industrial Revolutions for Impoverished Agrarian Nations. Theoretical Economics Letters, 8(11), 2594-2630. doi:10.4236/tel.2018.811166

Forrest, J. Y.-L., Shao, L., McKinney, R., \& Shao, D. (2020). (to appear). Firm performance and market expansion from the point of view of resources. International Journal of Business and Systems Research.

Galli, B. J. (2020). Continuous technological improvement using systems engineering principles to achieve sustainability: An investigation into related literature. International Journal of System Dynamics Applications, 9(3), 1-25. Advance online publication. doi:10.4018/IJSDA.2020070101

Government of Japan. (2015). https://www8.cao.go.jp/cstp/kihonkeikaku/5basicplan_en.pdf 
Hall, W., \& Pesenti, J. (2017). Growing the artificial intelligence industry in the UK. https://assets.publishing. service.gov.uk/government/uploads/system/uploads/attachment_data/file/652097/Growing_the_artificial_ intelligence_industry_in_the_UK.pdf

Haraguchi, N., Martorano, B., \& Sanfilippo, M. (2019). What factors drive successful industrialization? Evidence and implications for developing countries. Structural Change and Economic Dynamics, 49(June), 266-276. doi:10.1016/j.strueco.2018.11.002

Harmancioglu, N., Droge, C., \& Calantone, R. (2009). Strategic fit to resources versus NPD execution proficiencies: What are their roles in determining success? Journal of the Academy of Marketing Science, 37(3), 266-282. doi:10.1007/s11747-008-0125-x

Hermann, M., Pentek, T., \& Otto, B. (2016). Design principles for Industry 4.0 scenarios. The 49th Hawaii International Conference on System Sciences (HICSS), 3928-3937.

Karlsen, A. (2018). Framing industrialization of the offshore wind value chain - A discourse approach to an event. Geoforum, 88(January), 148-156. doi:10.1016/j.geoforum.2017.11.018

Kim, Y. J., \& Brown, M. (2019). Impact of domestic energy-efficiency policies on foreign innovation: The case of lighting technologies. Energy Policy, 128(May), 539-552. doi:10.1016/j.enpol.2019.01.032

Komkov, N. I., \& Kulakin, G. K. (2018). Technological innovations: Development, application and results. Studies on Russian Economic Development, 29(September), 558-572. doi:10.1134/S1075700718050064

Kozlenkova, I. V., Samaha, S. A., \& Palmatier, R. W. (2014). Resource-based theory in marketing. Journal of the Academy of Marketing Science, 42(April), 1-21. doi:10.1007/s11747-013-0336-7

Li, T., \& Ma, J. H. (2015). Complexity analysis of dual-channel game model with different managers' business objectives. Communications in Nonlinear Science and Numerical Simulation, 20(1), 199-208. doi:10.1016/j. cnsns.2014.05.012

Lieberman, M. B., \& Montgomery, D. B. (1988). First-mover advantages. Strategic Management Journal, 9(S1), 41-58. doi:10.1002/smj.4250090706

Lieberman, M. B., \& Montgomery, D. B. (2013). Conundra and progress: Research on entry order and performance. Long Range Planning, 44(4-5), 312-324. doi:10.1016/j.lrp.2013.06.005

Marc, S., Yann, B., \& Charly, B. (2018). Mission villani: for a meaningful artificial intelligence towards a French and European strategy. https://www.aiforhumanity.fr/pdfs/MissionVillani_Report_ENG-VF.pdf

Markides, C. C., \& Geroski, P. A. (2005). Fast second: How smart companies bypass radical innovation to enter and dominate new markets. Jossey Bass/Wiley.

Mayer, J. (2018). Digitalization and industrialization: Friends or foes? UN Conf. on Trade \& Development: https://unctad.org/en/PublicationsLibrary/ser-rp-2018d7_en.pdf

McGrath, R. G. (2013). The end of competitive advantage: How to keep your strategy moving as fast as your business. Harvard Business Review Press.

Miao, C. L., Fang, D. B., Sun, L. Y., Luo, Q. L., \& Yu, Q. (2018). Driving effect of technology innovation on energy utilization efficiency in strategic emerging industries. Journal of Cleaner Production, 170(1), 1177-1184. doi:10.1016/j.jclepro.2017.09.225

Nasution, F. B., Bazin, N. E., Rosalyn, R., \& Hasanuddin, H. (2018). Public policymaking framework based on system dynamics and big data. International Journal of System Dynamics Applications, 7(4), 38-53. Advance online publication. doi:10.4018/IJSDA.2018100103

NaudéW.NaglerP. (2018). Technological innovation, entrepreneurship and productivity in Germany, 1871-2015. $10.2139 /$ ssrn. 3107759

Nikabadi, M. S., \& Hakaki, A. (2018). A dynamic model of effective factors on open innovation in manufacturing small and medium sized companies. International Journal of System Dynamics Applications, 7(1), 1-26. Advance online publication. doi:10.4018/IJSDA.2018010101 
Olivera, M. (2018). The possibilities of industrialization and structural change for the periphery in the context of globalization. In V. Fernandez \& G. Brondina (Eds.), Development in Latin America (pp. 157-177). Palgrave Macmillan.

Omamo, A. O., Rodrigues, A. J., \& Muliaro, W. J. (2020). A system dynamics model of technology and society: In the context of a developing nation. International Journal of System Dynamics Applications, 9(2), 42-63. Advance online publication. doi:10.4018/IJSDA.2020040103

OSTP. (2012). A national strategic plan for advanced manufacturing. https://www.manufacturing-policy.eng. cam.ac.uk/documents-folder/policies/usa-a-national-strategic-plan-for-advanced-manufacturing-eop-nstc/view

O’Sullivan, A., \& Sheffrin, S. M. (2003). Economics: Principles in action. Pearson Prentice Hall.

Peteraf, M., \& Barney, J. (2003). Unraveling the resource-based tangle. Managerial and Decision Economics, 24(4), 309-323. doi:10.1002/mde.1126

Rostow, W. W. (1960). The Stages of Economic Growth: A Non-communist Manifesto. Cambridge University Press.

Singh, L. (2019). Competitiveness, skill formation and industrialization: The South Asian experience. In S. Chaturvedi \& S. Saha (Eds.), Manufacturing and Jobs in South Asia (pp. 213-227). Springer. doi:10.1007/978981-10-8381-5_9

Smith, A. (1776). The Wealth of Nations. Bantam Classics.

Snyder, K. A., Sulle, E., Massay, D. A., Petro, A., Qamara, P., \& Brockington, D. (2020). "Modern” farming and the transformation of livelihoods in rural Tanzania. Agriculture and Human Values, 37(March), 33-46. doi:10.1007/s10460-019-09967-6

Sobel, R. (1999). When Giants Stumble: Classic Business Blunders and How to Avoid Them. Prentice Hall.

Tiwari, S. K., Mishra, R. K., Ha, S. K., \& Huczko, A. (2018). Evolution of graphene oxide and graphene: From imagination to industrialization. ChemNanoMat : Chemistry of Nanomaterials for Energy, Biology and More, 4(7), 598-620. doi:10.1002/cnma.201800089

$\mathrm{Vu}$, K. M. (2018). Embracing globalization to promote industrialization: Insights from the development of Singapore's petrochemicals industry. China Economic Review, 48(April), 170-185. doi:10.1016/j. chieco.2017.01.003

Welch, J. (2019). Innovation questions \& answers. https://innovationcompany.co.uk/innovation-questions

Zhang, H. M., Zheng, Y., Zhou, D. Q., \& Long, X. L. (2018). Selection of key technology policies for Chinese offshore wind power: A perspective on patent maps. Marine Policy, 93(July), 47-53. doi:10.1016/j. marpol.2018.03.030

Zhao, H. C., Forrest, J. Y.-L., \& Jirasakuldech, B. (2018). A game analysis of trade dumping and antidumping. Theoretical Economics Letters, 8(14), 2860-2881. doi:10.4236/tel.2018.814179 
Jeffrey Yi-Lin Forrest was and is a professor of mathematics, economics, finance, and systems science in several different institutions of higher education. He is currently serving as the research coach of the School of Business at Slippery Rock University of Pennsylvania. His research interest covers a wide range of topics, including, but not limited to, accounting, economics, finance, mathematics, management, marketing, and systems science. As of the end of 2019, he has published over 500 research works, including 23 monographs and 27 special topic edited volumes.

Zhen Li is an Assistant Professor in the College of Business at Texas Woman's University. She received her Ph.D. degree from the University of North Texas. Her primary research interests include cross-cultural management, decision making, decision analysis, data analytics. She has published in European Journal of Operational Research, Annals of Operations Research, Asia Pacific Business Review, International Journal of Retail \& Distribution Management, and others.

Roger A. Solano has been a faculty member at SRU since 2009. He specializes in the science of making decisions based on mathematical or numerical models and techniques. He teaches Quantitative Analysis, Business Analytics, Operations Management and Supply Chain Management. His recent research includes interests include empirical and applied research in Intelligent Transportation System, the Analysis of Ag census data, and the application of new technologies to the learning process. Dr. Solano has a PhD in Industrial Engineering from NJIT and his undergraduate degree is from La Universidad del Zulia (Venezuela). He is a big promoter of diversity, equity and inclusion. He also champions Hispanic cultural programs on campus.

David J. Doorn earned his Ph.D. in economics with a minor in statistics from North Carolina State University in 2003. While finishing up his dissertation, David was employed as an economist with the U.S. Department of Labor, Bureau of Labor Statistics. He left the BLS in 2004 to pursue a career in academia, joining the faculty of the Department of Economics at the University of Minnesota - Duluth (UMD). In 2011 David completed the AACSB-Endorsed Post-Doctoral Program in Finance at Virginia Tech to become academically qualified in finance as well as economics. In 2012 David left UMD to take a position with the Department of Economics and Finance at West Chester University of Pennsylvania (WCU). David's primary fields of research include Macroeconomics, Econometrics and Regional Economics. 